LA-8055-P

DR. 1039

Proposal
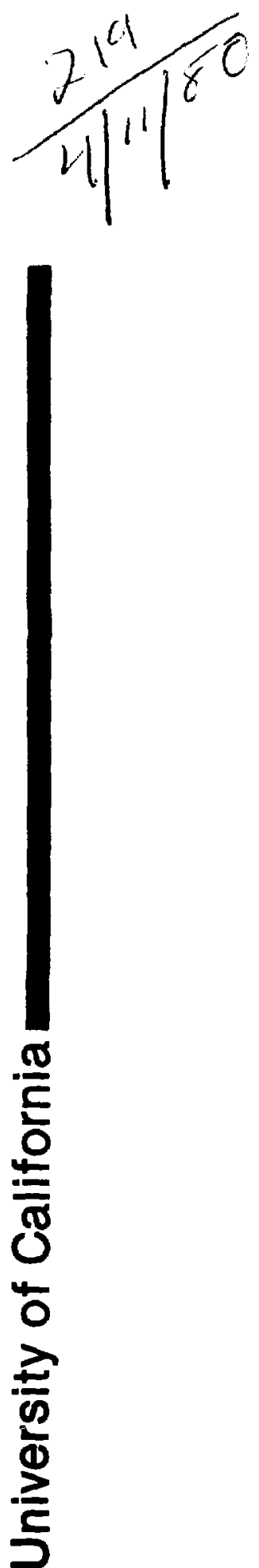

Application of Superconducting Coils to VAR Control in Electric Power Systems:

A Proposal 


\title{
Application of Superconducting Coils to VAR Control in Electric Power Systems: \\ A Proposal
}

\author{
H. J. Boenig \\ W. V. Hassenzahl
}




\title{
APPLICATION OF SUPERCONDUCTING COILS TO VAR CONTROL IN ELECTRIC POWER SYSTEMS: A PROPOSAL
}

\author{
by
}

H. J. Boenig and W. V. Hassenzahl

\begin{abstract}
During the last eight years, static VAR-control systems with thyristor-controlled, room-temperature reactors have been used in electrical systems for voltage control and system stabilization. In this proposal, we describe a new static VAR-control system that uses an asymmetrically controlled Graetz bridge and a superconducting de coil. Preliminary studies indicate that the proposed system will have lower overall losses and that its capital cost and electrical characteristics are comparable to those of a conventional system. We propose three- and four-year programs for developing the electronic circuitry and superconducting coils for VAR control, culminating in the installation and testing of an $~ 40$-MVAR system.
\end{abstract}




\section{INTRODUCTION AND SUMMARY}

Thyristor phase-controlled reactors with a parallel-connected capacitor bank are now used in static VAR systems to compensate for lagging load currents and to eliminate unbalanced loading of the three-phase power system., ${ }^{1,2}$ In principle, a static shunt compensator consists of three air core reactors arranged in a delta configuration and connected to a pair of antiparallel thyristors, as shown in Fig. 1. A three-phase capacitor bank provides a constant leading power factor. Reactor currents can be varied continuously from zero to the maximum value by proper phase control of the thyristor switches. The total losses of a static shunt compensator are given in Refs. 3-6. Compensators with a power rating of 20 to 100 MVAR connected to a $13.8-$ or $34.5-\mathrm{kV}$ bus typically have $1.2 \%$ losses. These losses can be broken down into $0.15 \%$ capacitor losses, $0.6 \%$ reactor losses, and $0.45 \%$ SCR losses. The absolute losses for a 40-MVAR system that is used as an example in this report are given in Table $\mathrm{I}$.

Based on the fact that low-frequency cryogenic coils generate low losses and $1 \mathrm{~kW}$ of installed power in an electric utility was worth about $\$ 2000$ in 1979 , we must determine whether a static VAR-control system can be built more economically using superconducting magnets. VAR control requires de superconducting coils because losses in $60-\mathrm{Hz}$ superconducting coils would be too high. Therefore, a direct replacement of the room-temperature coils in Fig. 1 by superconducting conse would not result in a system with lower losses.

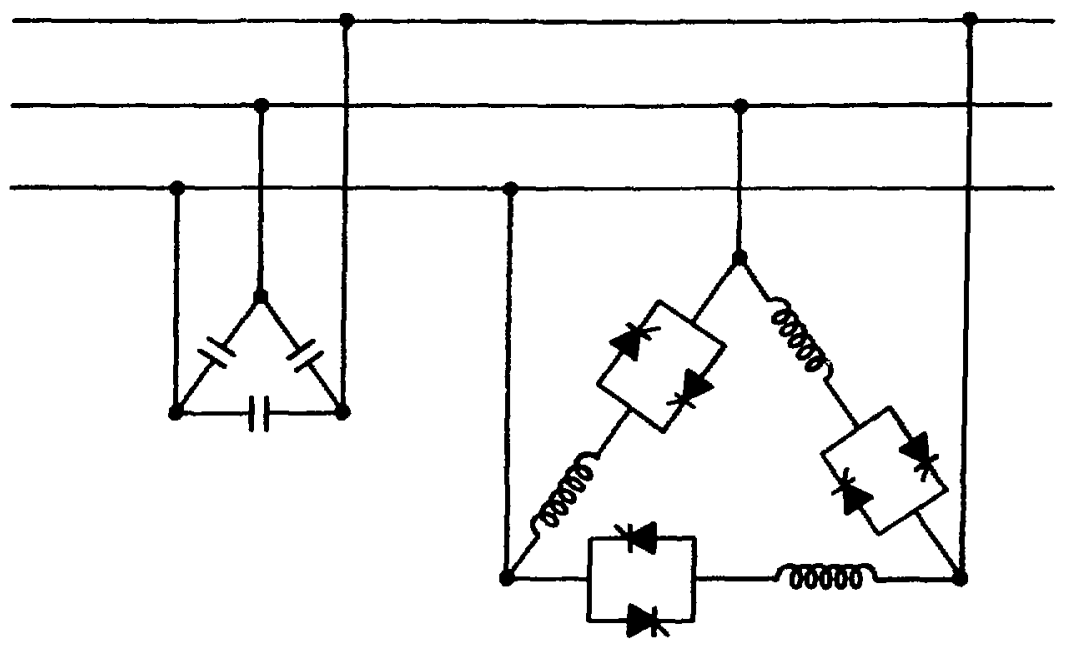

Fig. 1. Static shunt compensator circuit. 


\section{TABLE I}

\section{LOSSES OF A 40-MVAR CONVENTIONAL STATIC VAR-CONTROL SYSTEM}

\begin{tabular}{lr} 
Losses & $\mathrm{kW}$ \\
\cline { 2 - 2 } Capacitor & 60 \\
Reactor & 240 \\
SCR & 180 \\
Total & $\mathbf{4 8 0}$
\end{tabular}

A 6- or 12-pulse symmetrically controlled Graetz bridge, together with a room-temperature or superconducting dc magnet, is suitable for VAR control. ${ }^{7}$ However, such a system will have high losses when the reactive power is changed quickly because the coil current also changes quickly.

A Superconductor Application VAR-control (SAVAR) system, consisting of an asymmetrically controlled bridge and a superconducting reactor, will have low system losses because the current in the coil is essentially constant. The asymmetrically controlled 6-pulse bridge produces a $360-\mathrm{Hz}$ harmonic in both the coil and the line currents. The superconducting coil must be designed to have acceptably low losses at this frequency.

On the basis of our preliminary studies made at the Los Alamos Scientific Laboratory (LASL), we propose the design and construction of a 40-MVAR SAVAR system tied to a $13.8-\mathrm{kV}$ ac bus because it is large enough to be completely representative of commercial units and it will provide a valuable basis for estimating future marketability. Further, the nonconventional components, namely the superconducting coil and the refrigerator, are small enough to be well within the present state of the art.

\section{STATIC VAR SYSTEMS - CIRCUIT COMPARISONS}

A de coil can be used for VAR control with existing power electronies circuitry. Here we review a 6- and 12-pulse symmetrically controlled Graetz bridge circuit with a dc coil, describe an asymmetrically controlled Graetz bridge; and give a qualitative comparison of the characteristies of the three circuits. 


\section{A. Six-Pulse Graetz Bridge}

Figure 2 shows the 6-pulse Graetz bridge circuit, which allows the use of a de magnet for VAR control. In an ideal 6-pulse bridge, only reactive power is absorbed for a phase-delay angle of $90^{\circ}$. Continuous VAR control is achieved by varying the phase-delay angle for a few milliseconds, thereby changing the reactor current. Once the reactor current has reached its new value, the phase-delay angle is reset to $90^{\circ}$. During the change from one VAR value to another, real power is absorbed or fed back. If this circuit is used to compensate for fast VAR changes, the fast real-power change may be an undesirable feature. A superconducting coil in this scheme would have considerable losses because of the high di/dt.

\section{B. Twelve-Pulse Graetz Bridge}

Two 6-pulse Graetz bridges connected in series with a $30^{\circ}$ phase shift between their three-phase feeding systems result in a 12-pulse bridge, as shown in Fig. 3 . If the commutation reactances are neglected, such a 12-pulse bridge would be well suited for continuous VAR control by operating one 6-pulse bridge in the rectifier mode and the other in the inverter mode. The individual bridge voltages are controlled in such a way that the average voltage output is zero once the coil is charged. Continuous VAR control, from its maximum value to zero, is achieved with the real power always identical

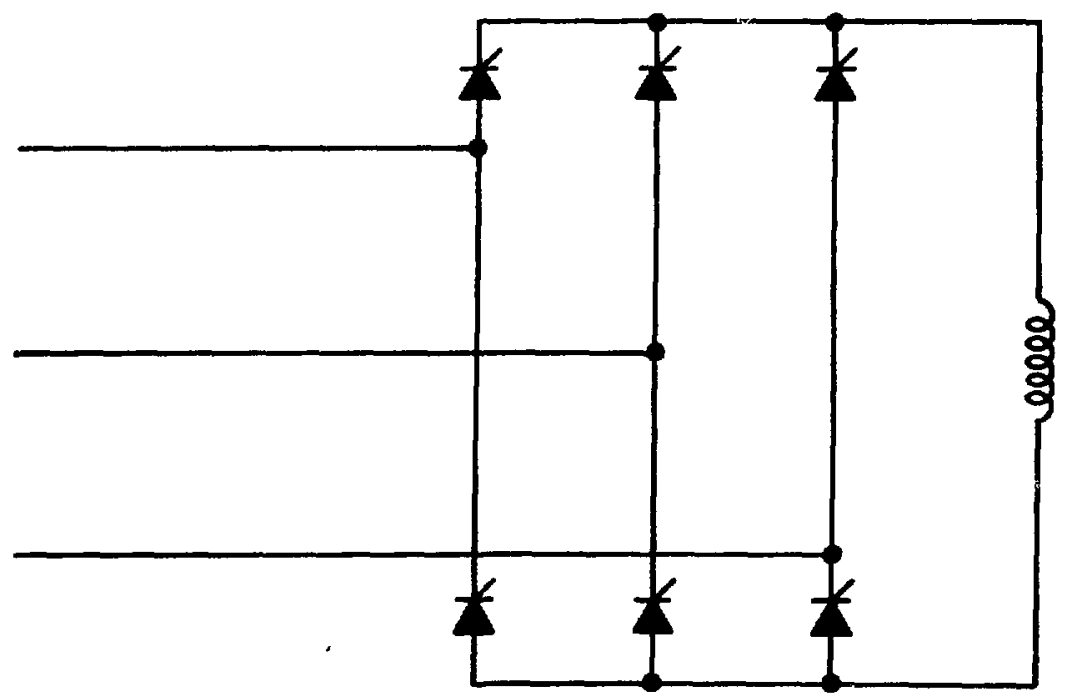

Fig. 2. Six-pulse Graetz bridge. 


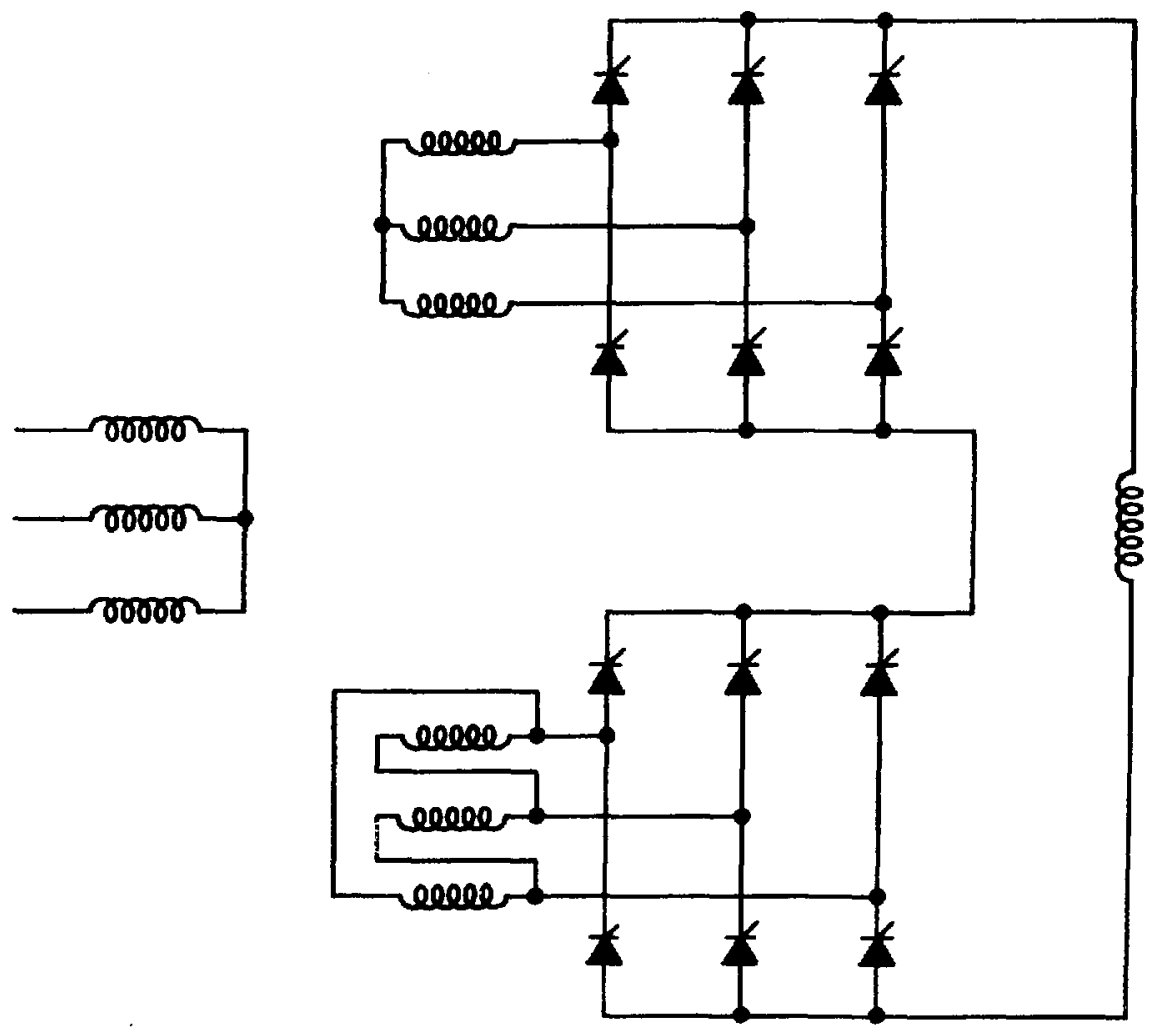

Fig. 3. Twelve-pulse Graetz bridge.

to zero. However, in a practical device, the commutation reactance cannot be neglected. Figure 4 shows the effect of this reactance on the VAR control. The reactive power can only be varied continuously by about $30 \%$ without changing the coil current and coil power. If a greater VAR change is required, the average coil current must be changed, thereby causing a real-power change. The 12-pulse circuit requires a converter transformer and reduces the harmonic content of the line current compared to the c-pulse circuit. Such systems have been installed successfully by industry, although they do not easily allow for individual phase control. As in the 6-pulse circuit, the superconducting coil would be subjected to fast current changes and thus would exhibit high losses when the system is installed to control fast-changing VAR demands.

\section{Asymmetrically Controlled Bridge}

The conduction sequence of the thyristors in 6- and 12-pulse bridges can be modified to obtain a line current that is $90^{\circ}$ out of phase with respect to the line voltage 


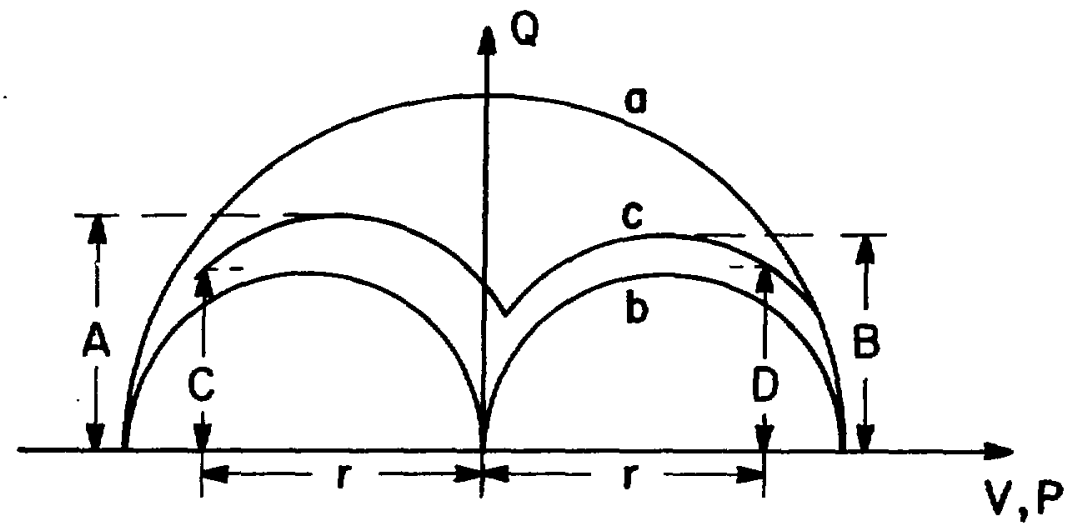

Fig. 4. Real-reactive power characteristic with sequence control of several converters.

(a) Single converter

(b) Two converters, overlap angle $\mu_{0}=00$

(c) Two converters, overlap angle $\omega_{0}=30^{\circ}$

(The reactive power $\mathrm{Q}$ can be varied in the range $\mathrm{C}+\mathrm{D}$ $\leqslant Q \leqslant A+$ B.)

and whose fundamental amplitude can be varied from zero to its maximum value without changing the coil current. To illustrate the method, consider the single-phase circuit of Fig. 5. If initially the coil is charged to its maximum current and then the phase-delay angle is changed to $90^{\circ}$, the system absorbs reactive power at its maximum rate. To decrease the line current to zero, and therefore the reactive power, the coil current must free-wheel through SCR 5 of Fig. 5 during part of a cycle. This is possible because the converter voltage is negative twice each cycle for a quarter of a period. During that time, the free-wheeling thyristor 5 is forward-biased.

Figure 6 shows the line currents, gating sequence, thyristor currents, reactor current, and reactor voltage for three values of conduction time of the free-wheeling $\mathrm{SCR}$. For the three conduction times the average coil voltage is zero, so the average coil current stays constant. The line current assumes the shape of a pulse-width modulated current and can be reduced continuously from its maximum value to zero, whereas the coil current stays constant. The line current is $90^{\circ}$ out of phase with respect to the line voltage, so the circuit absorbs only reactive power with an amplitude proportional to the line current. 


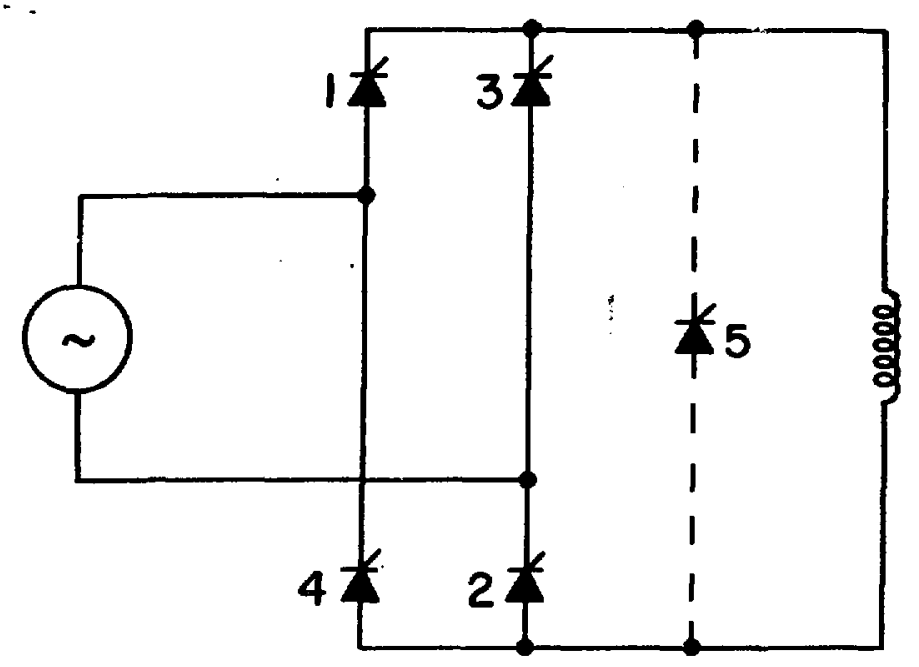

Fig. 5. Full-wave, single-phase Graetz bridge with freewheeling SCR.

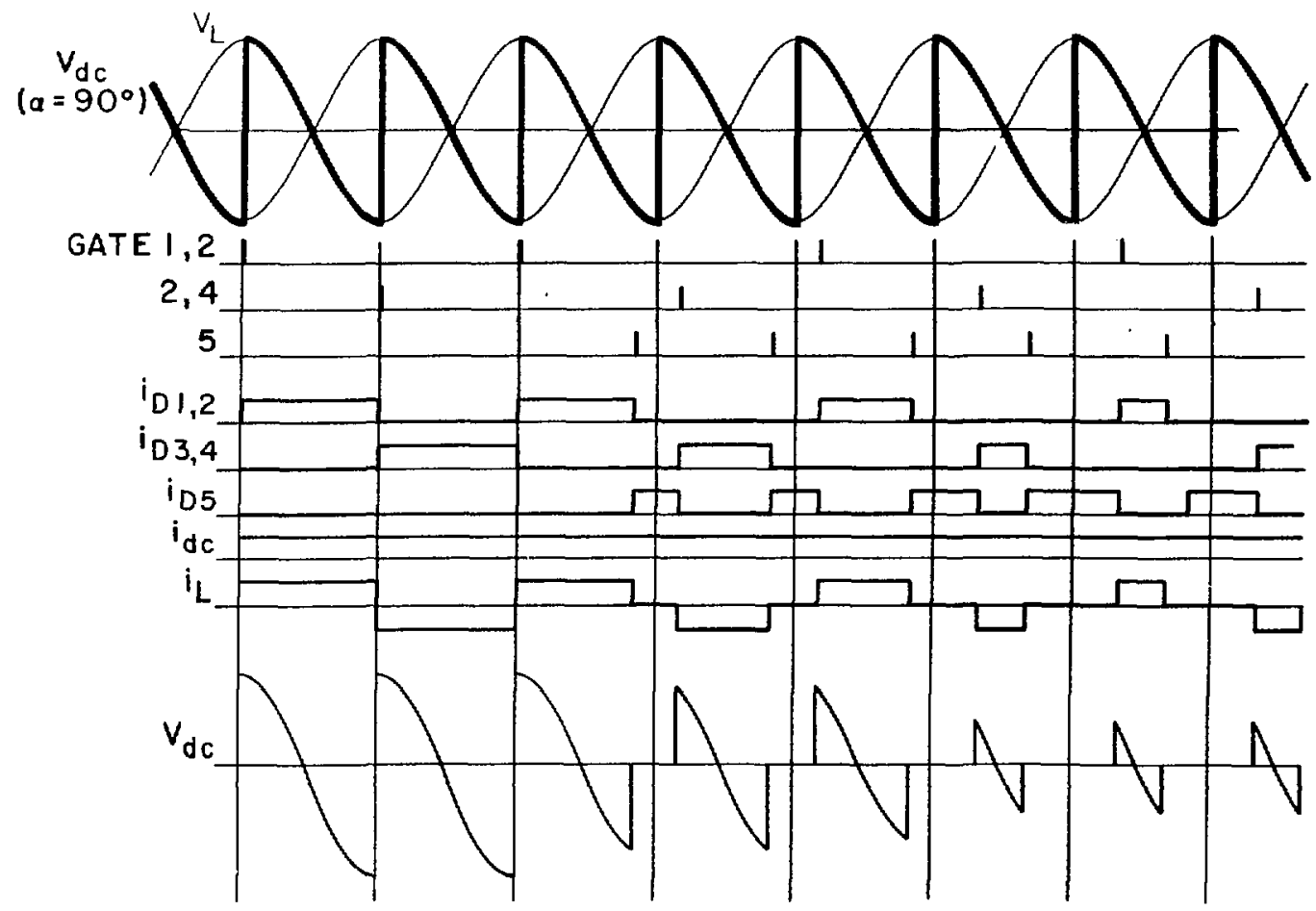

Fig. 6. Converter voltage, gating sequence, bridge current, and line current of an asymmetrically controlled single-phase Graetz bridge. 
The SAVAR circuit with a constant coil current seems to be very suitable for a superconducting coil. A close examination of the circuit in Fig. 5 reveals that the free-wheeling SCR is not necessary for proper functioning of the circuit, but that the bridge can be triggered to provide free-wheeling SCR action through two series-connected bridge thyristors during part of the cycle. The single-phase circuitry can be extended into the three-phase circuit of Fig. 7, with the free-wheeling SCR still shown for better understanding. The free-wheeling SCR can also be eliminated in this circuit. Figure 8 shows the absorption of different values of reactive power for three different amounts of free-wheeling SCR conduction time. The harmonic content of the line current, as shown in Fig. 9, has been calculated for a variable free-wheeling angle $\alpha$. Figure 10 shows the amplitude of the lowest frequency harmonics in a normalized form. The harmonic content of the line current is higher in this scheme than for the line current as generated by the circuit shown in Fig. 1. Therefore, a higher filter investment is required. Because the coil current is almost constant in the SAVAR system, independent of the value of reactive power absorption, we must determine whether the substitution of a superconducting for a conventional coil will reduce overall system losses.

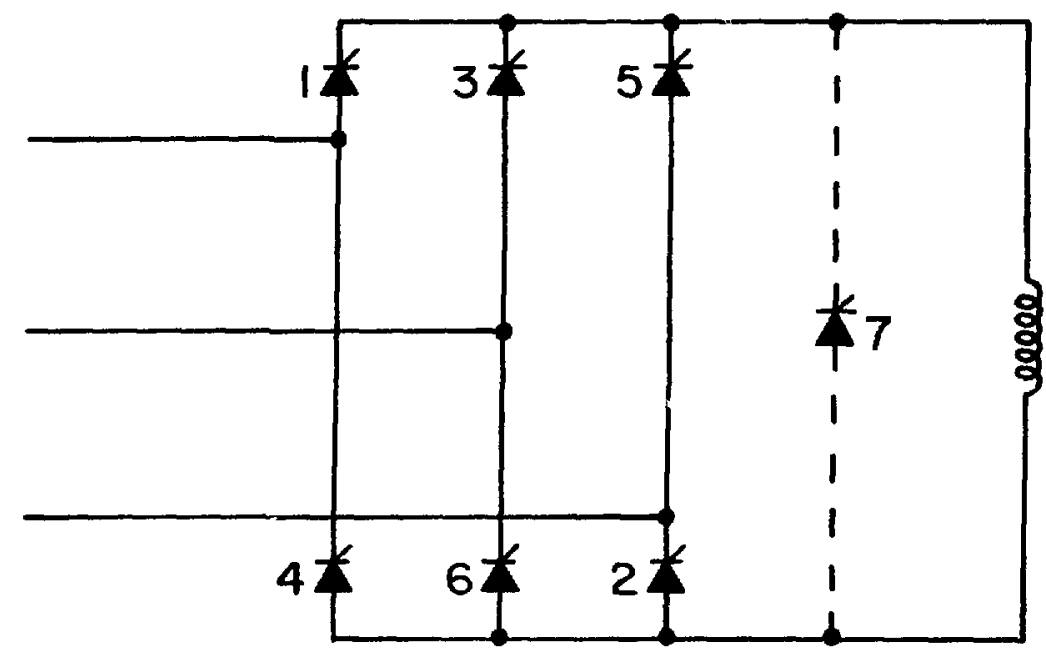

Fig. 7. Full-wave, three-phase bridge with free-wheeling SCR. 


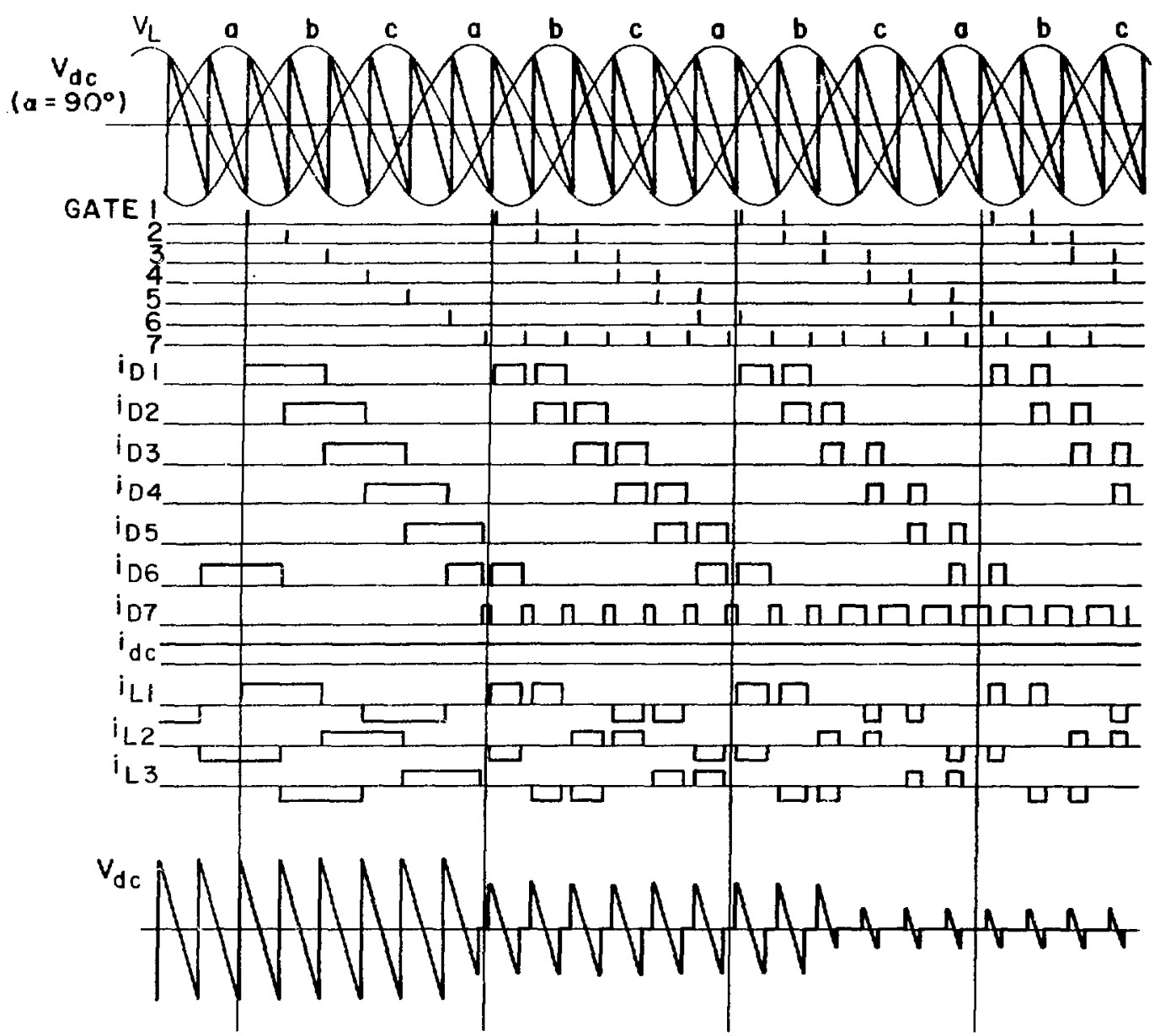

Fig. 8. Converter voltage, gating sequence, bridge current, and line current of an asymmetricaliy controlled, three-phase Graetz bridge.

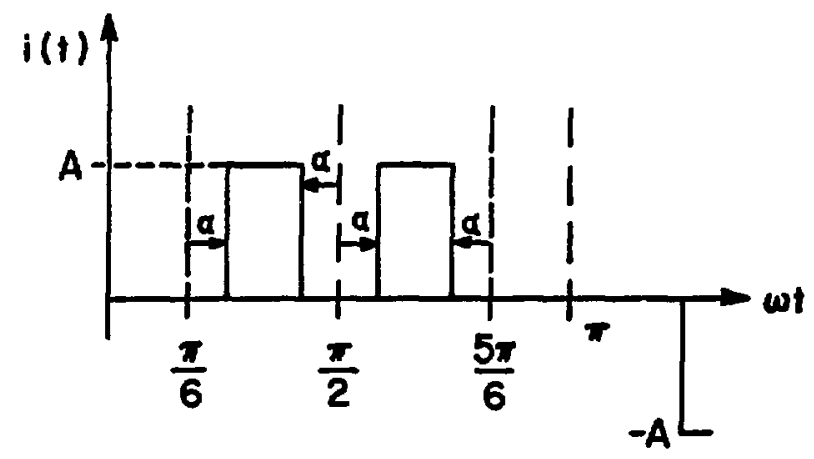

Fig. 9. Line current of an asymmetrically controlled, threephase Graetz bridge with free-wheeling SCR. 


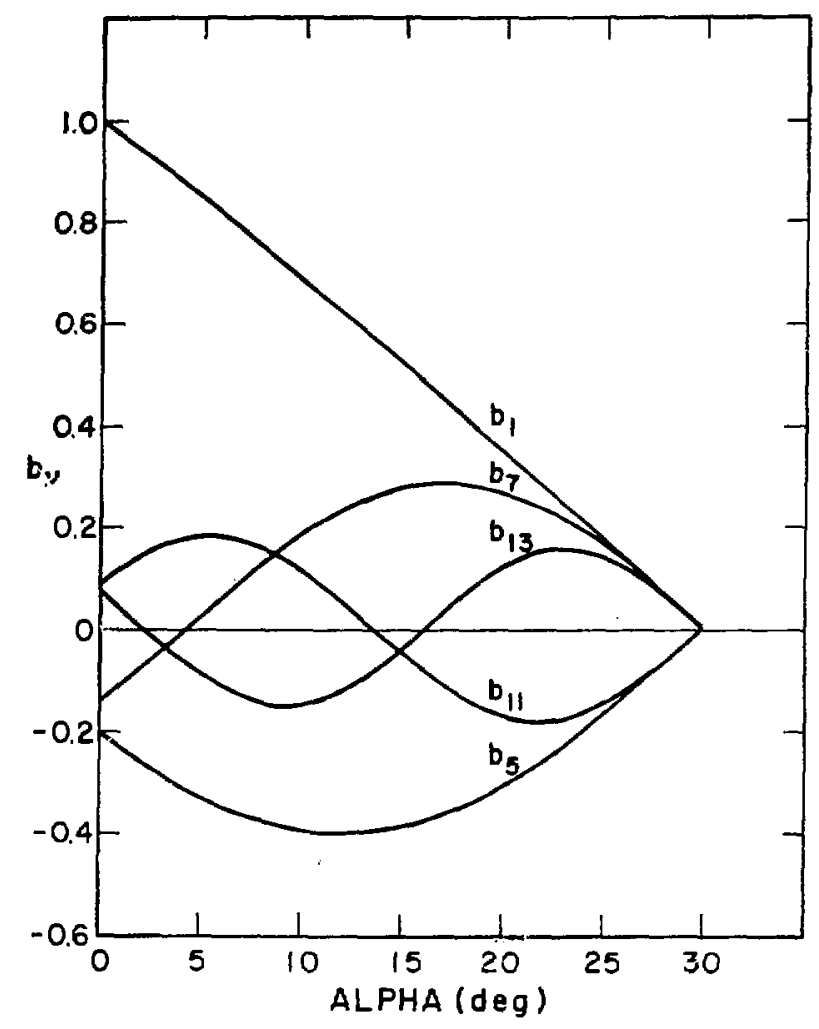

Fig. 10. Relative amplitude of fundamental and higher harmonic currents vs free-wheeling angle $\alpha$, where $b_{\nu}(\alpha)$ is the ratio of the $\nu$-th harmonic to the fundamental at $\alpha=0$.

\section{SUPERCONDUCTING COIL}

\section{A. Coil Design}

Superconductivity is a phenomenon exhibited by certain materials at very low temperatures. These resistanceless substances can carry a constant cur rent and have no heating or losses. While the current in and/or magnetic field on these substances is changing, however, they exhibit a resistive characteristic. The heat associated with their ac resistance must be removed at a low temperature, typically about $4 \mathrm{~K}$. Because of inherent thermodynamic effects and the various process inefficiencies, nearly $1000 \mathrm{~W}$ of room-temperature power are required to remove $1 \mathrm{~W}$ at $4 \mathrm{~K}$. For this reason, it is desirable to have extremely low losses in a superconducting coil.

The heating in a superconducting coil depends on the magnitude of the field variation and the quantity of superconductor in the coil. To design a superconducting 
TABLE II

COIL CHARACTERISTICS FOR A 40-MVAR SAVAR SYSTEM

$\begin{array}{lc}\text { Line voltage } & 13.8 \mathrm{kV} \\ \text { Average current } & 2140 \mathrm{~A} \\ \text { Maximum current variation } & \pm 10 \% \\ \text { Minimum inductance } & 35 \mathrm{mH} \\ \text { Maximum losses @ } 300 \mathrm{~K} & <50 \mathrm{~kW} \\ \text { Maximum losses @ } 4 \mathrm{~K} & <50 \mathrm{~W}\end{array}$

coil for a VAR-control system, it is necessary to make some choices as to acceptable sizes, capacities, magnetic fields, and losses. For comparison, a 40-MVAR system is used as an example. The coil characteristics for a 40-MVAR system are determined mainly by the total system economics and the acceptable losses; a reasonable goal would be to have less than half of the conventional coil losses.

If the 40-MVAR SAVAR system is tied to a $13.8-\mathrm{kV}$ line, the current in the coil must be $2140 \mathrm{~A}$ and the peak-to-peak, $360-\mathrm{Hz}$ voltage measured across the coil is 18.6 kV. Figure 8 shows that the coil voltage has six positive and six negative spikes during a period. Because of harmonic effects on the ac system, the variation in coil current cannot be allowed to exceed about $\pm 10 \%$. The coil inductance may be determined from the relation $\mathrm{V}=\mathrm{L}$ (di/dt) to be about $35 \mathrm{mH}$. The stored energy in the smallest possible coil that can be considered is $\mathbf{8 0} \mathrm{kJ}$. For convenience, a 100-kJ coil is considered below.

The coil characteristics, determined directly by the VAR requirement, are given in Table II. Note that the field density in the reactor is a free parameter. Several different coil geometries and types were evaluated to determine the minimum losses in a coil subjected to the specified charge-discharge cycle. The losses of a simple 3-T solenoid were too large to be acceptable. Because losses are smaller at lower fields, a large coil with a 500-G peak field was considered. Unfortunately, a 2-m-diam, 5-m-long coil is too large, and the cryostat ${ }^{*}$ is too costly for consideration.

The reactor proposed here is similar to a conventional inductor. A superconducting coil, in conjunction with a warm iron core and yoke, forms a relatively small system. The volume of iron required depends on the total stored energy, the

* A cryostat or dewar is a set of vessels, one inside the other, with alternating insulating spaces and regions at increasingly lower temperatures. A well-known example is the vacuum-insulated, glass thermos bottle. 
permeability, and the applied field. At $225 \mathrm{Oe}$, the permeability of mild steel, relative to a vacuum, is about 70 and the stored energy is about $43 \mathrm{~kJ} / \mathrm{m}^{3}$. Thus, about $2.4 \mathrm{~m}^{3}$ (ll tonnes) of iron will be required to store $100 \mathrm{~kJ}$.

The exact shape of the iron is not extremely important so long as there is a continuous, low-reluctance path of ferromegnetic material to channel the magnetic flux. Because such a small amount of iron is required, having the entire structure in a helium bath would simplify the magnet design. Unfortunately, all ferromagnetic materials exhibit hysteresis to a greater or lesser degree when they are subjected to an alternating magnetic field. For a steel that would be used as a transformer core, the energy loss associated with a full-cycle zero field to saturated negative field to saturated positive field and return to zero is typically 0.1 to $0.15 \mathrm{~J} / \mathrm{kg} /$ cycle, which is sufficient to heat up a room-temperature sample by $0.0003^{\circ} \mathrm{C}$. At $4 \mathrm{~K}$ the specific heat of iron is about 300 times less than at $300 \mathrm{~K}$; thus, a full cycle would raise the temperature by $0.1 \mathrm{~K}$. At a $360-\mathrm{Hz}$ rate and with each oscillation $1 / 10$ of a full cycle, the temperature will inerease 3 $\mathrm{K}$ per second. This loss would make the refrigeration requirements of a coil with cold iron so large that the superconducting VAR-control system would not be an attractive alternative to a conventional system. Therefore, coil configurations with roomtemperature iron must be considered.

The iron that forms a continuous magnetic path may be made in various geometries. The form chosen for this report (Fig. 11) is cylindrically symmetric and is composed of four iron sections, each of which may be laminated to reduce losses. The first section is a 0.5 -m-diam, l-m-long central core; the second is a $0.08-\mathrm{m}$-thick, 1.1-m-o.d outer ring. These sections are connected by two 0.125-m-thick, 1.1-m-o.d. disks. The superconducting coil will be located in the annular space formed by these four pieces and will be rather modest as far as superconducting coils go. It will be about $\mathbf{0 . 8}$ $\mathrm{m}$ long and $0.7-\mathrm{m}$ diam and will have about 70 turns. The total volume of superconductor will be only $150 \mathrm{~cm}^{3}$.

the recommended structure for the coil and cryostat is shown in Fig. 12. The coil is cooled by a liquid helium bath and the helium container is made of epoxy fiber glass. Epoxy fiber glass is necessary because eddy currents would be induced in a metallic vessel and the heat produced would have to be removed from the $4 \mathrm{~K}$ helium bath. This argument does not apply to the room-temperature portion of the vacuum vessel, which may be made of stainless steel, as is typical of cryogenic vessels of this size.

The heating in the 40-MVAR SAVAR coil, consisting mainly of hysteresis and eddy-current losses, will be quite modest. By using a formula from Turck, ${ }^{8}$ the hysteresis losses $P_{\mathbf{H}}$ in the superconductor may be found from 


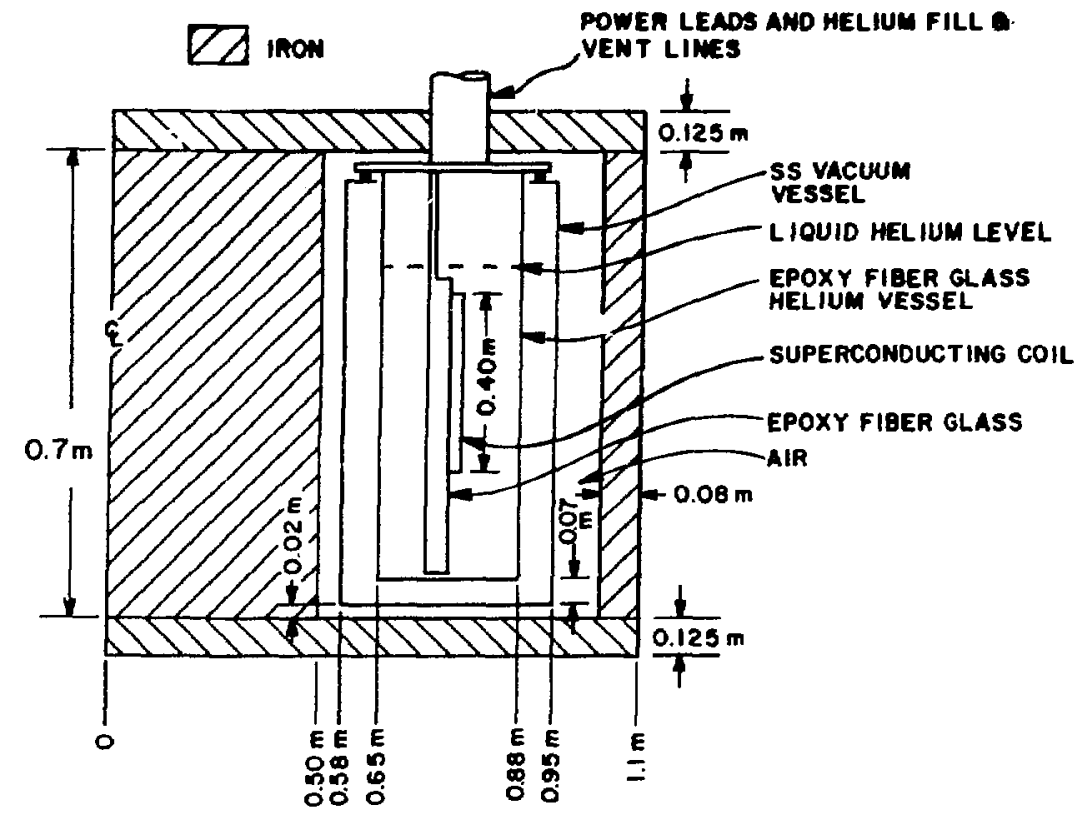

Fig. 11. A detailed cross section of the SAVAR coil showing the sizes of various components.

$$
P_{H}=\frac{{ }_{c}{ }_{c} d_{\omega} B_{o}\left(1+\varepsilon^{2}\right)}{2 \pi\left(1+\theta^{2} \omega^{2}\right)^{\frac{1}{2}}} \quad V_{S C} \text {, }
$$

where $J_{c}$ is the critical current at the applied field, $J_{c} \approx 10^{10} \mathrm{~A} / \mathrm{m}^{2} ; \mathrm{d}$ is the diameter of the superconducting filaments, $d \approx 10^{-5} \mathrm{~m} ; \omega$ is the angular frequency of the field and current variation; $B_{0}$ is the maximum value of the field change; $\epsilon$ is a geometrical factor associated with the superconductor; and $\theta$ is the time constant associated with the diffusion of current into the conductor. For an ll-strand, 0.5-mm-diam cable, $\theta \omega \approx$ 0.1 and the total hysteresis losses are

$$
P_{H} \approx 7 \mathrm{~W} \text {. }
$$

The eddy-current losses $P_{E}$ are a sum of two terms, both of which relate to the conductor geometry. 


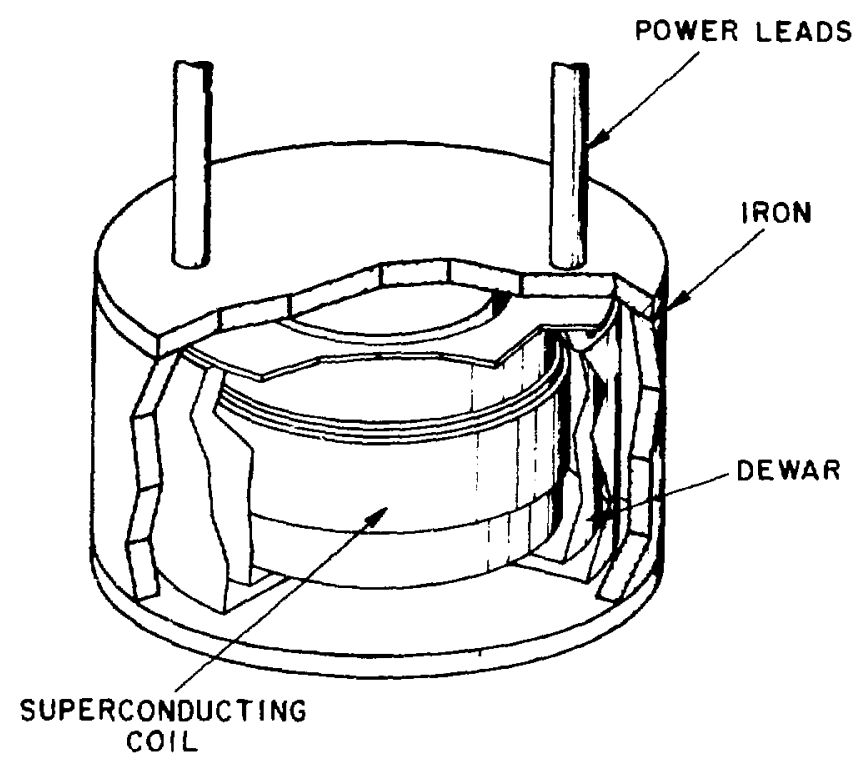

Fig. 12. A sectioned isometric view of the SAVAR coil showing the major components.

$P_{E}=\left\{\left(\frac{R_{f}}{R_{c}}\right)^{2} \frac{\theta^{2} \omega^{2} B_{0}{ }^{2}}{2 \mu_{0}\left(1+\theta^{2} \omega^{2}\right)}+\left[1-\left(\frac{R_{f}}{R_{c}}\right)^{2}\right] \frac{\theta^{2} \omega^{2} B_{0}{ }^{2}}{2 \mu_{0}\left(1+\theta^{2} \omega^{2}\right)}\right\} \nu_{c}$,

where $R_{f}$ and $R_{c}$ are the radii of the filaments and conductor strands, respectively.

For the 40-MVAR coil the eddy-current loss is

$P_{E} \approx 0.6$ W.

The superconducting coil will have power leads that bring the current to the coil in the liquid helium. These leads will vaporize and heat about six liters of helium each hour to room temperature. In addition, some radiation from room temperature will reach the $4 \mathrm{~K}$ cryostat. If the system is superinsulated,* this loss will be $<1 \mathrm{~W}$.

* Superinsulation consists of many layers of aluminized $B_{M y l a r}$ in a vacuum. This type of insulation is most effective for cryogenic systems. 
LOSSES AND HEATING IN THE 40-MVAR SUPERCONDUCTING COIL

\begin{tabular}{lc}
\multicolumn{1}{c}{ Heat Source } & \multicolumn{1}{c}{ Watts } \\
Hysteresis losses & 7.0 \\
Eddy-current losses & 0.6 \\
Lead losses & $6 \ell / \mathrm{h}$ or 18.0 \\
Radiation losses & $<1.0$ \\
Conduction heat leak & $<5.0$ \\
Transfer-line heat leak & $<\frac{<.0}{39.6}$
\end{tabular}

There will be a force between the warm iron and the cold coil, So long as the system is completely symmetric this force will be completely balanced and, although the outward radial force at the center line of the coil may be large, there will be no net force to displace the coil with respect to the iron. As soon as the coil is displaced from a symmetrical position the forces will tend to push it farther off center. A structure that can withstand the force associated with the maximum anticipated displacement must be supplied. This structure has not keen analyzed completely, but it may be large enough to produce about $5 \mathrm{~W}$ of heat leak into the $4 \mathrm{~K}$ helium bath. A summary of all the coil losses is given in Table III. The total equivalent heat load of $40 \mathrm{~W}$ will require $<40 \mathrm{~kW}$ of power at room temperature.

\section{B. Refrigerator}

The requirements for a refrigerator, as given in Table II for the 40-MVAR system, are within the capacity of all but the smallest helium refrigerators available today. $A$ typical unit, such as the CTI 1400,* could easily satisfy these requirements at a reasonable cost.

The refrigerator and cryogenic system consists of the central refrigerator unit, one or more compressors, a helium-storage facility, and a set of special pipes for interconnecting these components and the superconducting coil. A helium-flow diagram for the SAVAR system is shown in Fig. 13.

If many superconducting VAR-control systems were fabricated, it would be useful to consider the possibility of building the coil, cryostat, and refrigerator as a single unit to reduce both cost and transfer-line losses.

*Manufactured by Cryogenic Technology Inc., Waltham, MA 02154. 


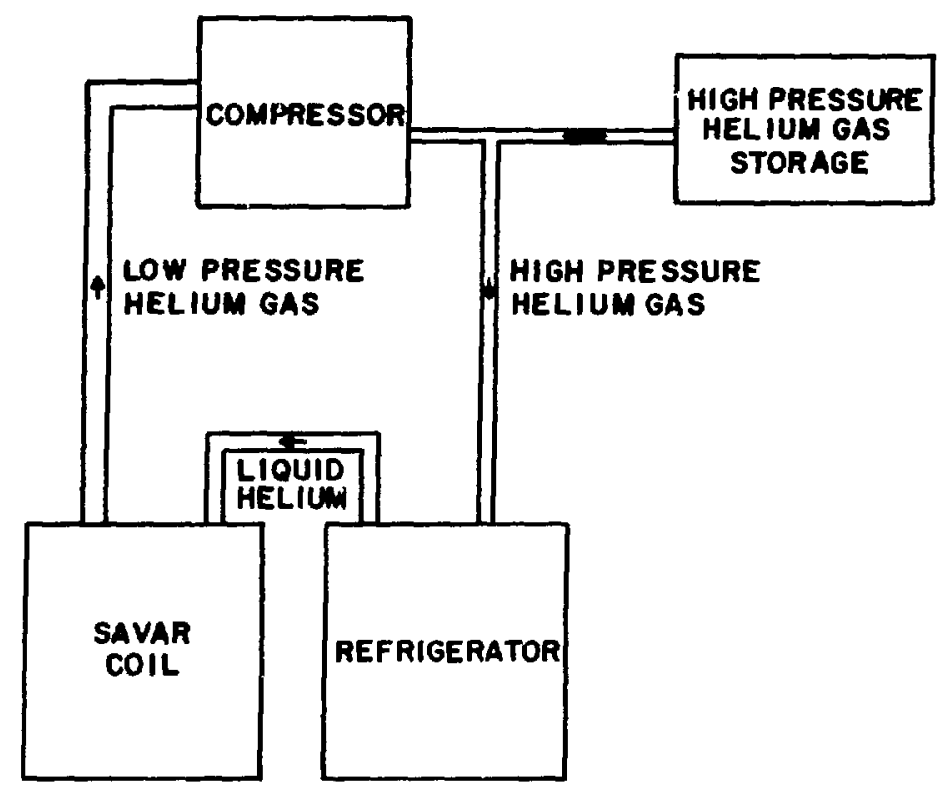

Fig. 13. Helium flow circuit for the SAVAR system.

IV. AN INITIAL COMPARISON OF SAVAR AND CONVENTIONAL VAR-CONTROL SYSTEMS

The important parameters of the 40-MVAR conventional and superconducting VAR-control systems are summarized in Table IV. The major differences are in the reactors and, in particular, in the power savings associated with the superconducting unit. The cost of the power electronies and the thyristor losses, as listed in Table V, are assumed to be the same for both systems. 


\section{COMPARISON OF 40-MVAR CONVENTIONAL AND SUPERCONDUCTING} VAR-CONTROL SYSTEMS

Component or

Characteristic

Reactor(s)

Reactor cooling

Reactor losses

Power conversion

Thyristor units

Thyristor current rating

Thyristor voltage rating

Filter requirement
Thyristor-Controlled Room-Temperature Reactors

Three room temperature

$13.8 \mathrm{kV}, 0.9 \mathrm{kA}$

Natural convection

$240 \mathrm{~kW}$

Thyristor switch

6

$0.9 \mathrm{kA}$ half sine wave

$13.8 \mathrm{kV}$

Smaller
Thyristor-Controlled

Supercondueting Coil

One superconducting

$9.8 \mathrm{kV}, 2.14 \mathrm{kA}$

Helium refrigerator 20 to $40 \mathrm{~kW}$ (refrigerator power) Thyristor bridge 6

$2.14 \mathrm{kA}, 120^{\circ}$ conduction

$9.8 \mathrm{kV}$

Higher

TABLE V

COST COMPARISON OF CONVEN'TIONAL AND SUPERCONDUCTING

VAR-CONTROL SYSTEMS

Component

Reactor

Cooling system

Amortized operating and maintenance costs ${ }^{a}$

Total excluding power equipment

Power equipment ${ }^{b}$

( $\$$ Thousands)

\author{
Conventional
}

300

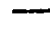

300

600

1000
Superconducting 50

160

80

290

1000

\footnotetext{
a

bThyristors, capacitors, switchgear, etc.
} 
Three- and four-year, three-phase, comprehensive research, development, and demonstration programs are proposed to demonstrate the concept of a superconducting coil for VAR control. This program could begin as soon as funds are available; FY 80 appears to be a likely goal based on external funding considerations.

The initial stage of the program should last for about one year. Several different areas will be studied.

1. A small VAR-control system with a 10- to 50-kVA converter and available conventional and superconducting coils will be tested to prove the principle. The unit will be tied to a $220-\mathrm{V}, 3$-phase line.

2. The components of the superconducting VAR-control system will be evaluated and an optimized 40-MVAR reference design will be established. Specific topies will include the superconducting coil, use of cold vs warm iron, need for laminated iron, filter requirement, control design for an asymmetrically controlled bridge, and tradeof fs between 6- and 12-pulse bridges.

3. The cost of the proposed, optimized superconducting VAR-control system will be determined by LASL with input from electronic and superconducting component suppliers.

4. An outside contractor will make an independent evaluation to study the effectiveness of static VAR generators in terms of voltage regulation, load-flow management, and transient and dynamic stability.

5. If the cost estimate proves favorable and the model system functions satisfactorily, a detailed program will be developed for the second phase and a decision will be made whether to continue the research effort.

The second phase will consist of the design, construction, and testing of a superconducting VAR-control unit of meaningful size. The 40-MVAR capacity is not definite, but it appears to be a good choice because the superconducting coil for a unit of this size is probably as small as would be built. The cost for a reactor with half the 
inductance would cost about the same. A realistic test could still be performed even if the thyristor bridge for the system test is only 2 or 3 MVAR.

The final, or third, phase will consist of a full-scale test of the unit on a utility system with the then-existing superconducting coil at a utility location where continuous VAR control is needed. Perhaps this test could be jointly supported by the Department of Energy (DOE), the Electric Power Research Institute (EPRI), and the hosting utility. Such a collaborative effort might lead to the most rapid acceptance of this technology by the utility industry.

The costs of the three phases of this program, listed in Table VI, are given in some detail so that costs of some items that may not have to be obtained can be identified.

The estimated costs of the components required for the SAVAR system, given in Table VI, are somewhat higher than those given in Table $V$ because they include one-of-a-kind development costs. The costs are based on a three-year program to design, construct, and test a SAVAR system. The annual costs are given in Table VII for a three-year program and in Table VIII for a four-year program. The total cost for the three-year program is $\$ 3185 \mathrm{k}$ and for the four-year program is $\$ 3790 \mathrm{k}$. There is no technical reason for extending the program to four years because the development, construction, and tests outlined here can be comfortably completed in three years.

The costs in Tables VII and VIII are based on System B of Table VI. System B uses helium gas-handling equipment, the converter, and the refrigerator from the Bonneville Power Administration (BPA) stabilizing unit. If this equipment is not used, the total program costs given in Tables VII and VIII will increase by $\$ 775 \mathrm{~K}$ plus contingency and some additional staff. In round numbers, use of the equipment for the BPA stabilizing unit will save about $\$ 1000 \mathrm{k}$. 
TABLE VI

ESTIMATED COSTS FOR THE DEVELOPMENT OF A
SUPERCONDUCTING VAR-CONTROL SYSTEM

$\underline{\text { System A }}^{a}$

( $\$$ Thousands)
Energy storage coil

Supereonductor (1st \& 2nd-MP)

Structure and support (1st \& 2nd-MP)

Engineering and fixtures (lst \& $2 n d-M P$ )

Manufacture and assembly (2nd-MP)

Converters

3 MVAR (2nd-C)

40 MVAR installed (3rd-C)

Dewar and electrical leads

(lst \& 2nd-MP)

Refrigerator (2nd-C)

Transfer lines and cryogenics

equipment (2nd-MP)

Instrumentation and miscellaneous

equipment (2nd-MP)

Iron (1st \& 2nd-MP)

Installation (2nd-MP)

Total (FY 80 \$s)

$\begin{array}{rr}80 & 80 \\ 50 & 50 \\ 100 & 100 \\ 25 & 25\end{array}$

35

$1000^{\mathrm{d}}$

$-0-$

$1000^{d}$

80

80

160

15

330

30

60

30

15

350

$\frac{350}{2300}$
30

100

$\bar{a}$ System A includes all items in the three-phase program.

b System B uses helium gas-handling equipment, the converter, and the refrigerator from the BPA stabilizing unit. Some modification costs are required for these units.

c Numbers in parentheses indicate the year after the program starts in which funds are to be obligated, based on the three-year program. Letters in parentheses designate C-capital, MP-major procurement.

d The major cost item is the 40-MVAR converter. Because this is not a development item, it is possible that its cost can be shared by DOE, EPRI, and the utility where it is installed. 
$\underline{\text { FY }}$

$\underline{\text { lst }}$

( $\$$ Thousands)

2nd

3rd

Energy storage coil

Superconducting cable

20

10

60

Structure and support

60

40

Engineering and fixtures

40

Manufacture and assembly

25

Converters

I MVAR

40 MVAR

1000

Dewar and electrical leads

10

70

Refrigerator

15

Transfer lines and cryogenic equipment

30

Instrumentation and

miscellaneous equipment

Iron

Installation

Subtotal (FY 80 \$s)

Independent VAR-control study

Contingeney and inflation

75

Personnel

Total

125

500

500

$\overline{310}$

$\overline{1000}$

$\overline{1950}$ 
TABLE VIII

COSTS FOR SYSTEM B FOR FOUR-YEAR PROGRAM

\begin{tabular}{|c|c|c|c|}
\hline \multirow[b]{2}{*}{$\underline{\mathbf{F Y}}$} & \multicolumn{3}{|c|}{ ( $\$$ Thousands) } \\
\hline & lst & 2nd & 3rd \\
\hline
\end{tabular}

Energy storage coil

Superconducting cable

60

20

Structure and support

40

10

Engineering and fixtures

40

50

10

Manufacture and assembly

25

Converters

1-MVAR

40-MVAR

1000

Dewar and electrical leads

Refrigerator

Transfer lines and cryogenic

equipment

Instrumentation and

miscellaneous equipment

Iron

Installation

Subtotal (FY 80 \$s)

$\begin{array}{cccc} & 5 & 10 & \\ & 15 & 15 & \\ \overline{40} & \overline{235} & \overline{100} & \\ & & \overline{250} & \overline{1000}\end{array}$

$50 \quad 30$

15

15

15.

Independent VAR-control study

75

Contingency and inflation

Personnel

Total

100

45

$120 \quad 600$

$\overline{215}$

$\frac{400}{680}$

$\frac{500}{870} \quad 500$ 


\section{CONCLUSIONS}

We have developed a circuit that uses small superconducting de coils with a storage capacity of about $100 \mathrm{~kJ}$ for VAR control. Initial studies show that the coil losses can be reduced considerably compared to room-temperature coils and that the equipment costs are about equal to those of a conventional system. A VAR-control scheme with a superconducting coil can be built with present state-of-the-art technology. System reliability is expected to be high because a small helium refrigerator with an established performance record can be used and the superconducting coil can be designed conservatively.

\section{REFERENCES}

1. Proceedings: Transmission Static VAR Systems Seminar, EPRI report EL-1047-SR, (April 1979).

2. F. J. Ellert and R. J. Moran, "HVDC and Static VAR-Control Applications of Thyristors," Int. Semiconductor Power Converter Conf., IEEE No. 77 CH 1183-31A (1977).

3. R. J. Moran, C. H. Titus, and J. B. Tice, "Solid State Converters for Power System Voltage Control," Proceedings of the American Power Conference, 1041-1047, 37, (1975).

4. L. Gyugyi, Westinghouse Electric Corp., personal communication, March 1979.

5. J. W. Motto, D. P. Orange, and R. A. Otto, "The Static VAR Generator and Alternative Approaches to Power Systems VAR Compensation," Proceedings of the American Power Conference, 1032-1040, 37, (1975).

6. W. L. Davis and H. F. Brinker, "Static VAR System Controls Line Voltage," Electrical World, July 1978.

7. J. D. Pahud, "The Reactive Power Compensation of the CERN PS-Booster Power Supply," Proceedings Int. Conf. Magnet Technology, Brookhaven, 718-724, (1972).

8. B. Turck, "Losses in Superconducting Multifilament Composites under Alternating Changing Fields," Los Alamos Scientific Laboratory report LA-7639-MS (March 1979).

9. "Transformers: Gaining on the Losses," EPRI journal, 4, July/August 1979, p. 8. 